\title{
UN NUEVO PARLAMENTO \\ FRAGMENTADO PARA LOS 40 AÑOS \\ DE LA CONSTITUCIÓN
}

\author{
PIEDAD GARCÍA-ESCUDERO MÁRQUEZ
}


SUMARIO

I. INTRODUCCIÓN II EL FIN DEL BIPARTIDISMO NO SE REFLEJA SÓLO EN EL PLENO DE LA CÁMARA Y EN LAS COMISIONES. 1. Mesa del Congreso de los Diputados. 2. Presidencia y Mesa de las Comisiones. II. EL ESTATUTO DE LOS DIPUTADOS. III. LA FUNCIÓN LEGISLATIVA: ¿PUEDE UN GOBIERNO GOBERNAR SIN LEGISLAR? 1. Iniciativa legislativa. 2. Intentos de suplir la falta de iniciativa. a) Las subcomisiones como medio de consensuar iniciativas legislativas. b) El procedimiento de lectura única para textos no tan sencillos ni unánimes 3. El procedimiento legislativo en Comisión. La ponderación de voto en las ponencias. 4. El decreto-ley no constituye alternativa a la ley. IV. LA FUNCIÓN PRESUPUESTARIA: EL PRESUPUESTO, VOTO A VOTO V LA FUNCIÓN DE CONTROL. LA RESPONSABILIDAD DEL GOBIERNO. 1. Instrumentos ordinarios de control e indirizzo 2. Las comisiones de investigación. 3. La reprobación de ministros y otras autoridades 4. La moción de censura testimonial que se gana en la calle. VI. LA FUNCIÓN DE NOMBRAMIENTO. VII. LA FUNCION INTERNACIONAL 1. Autorización de convenios internacionales. 2. Política de la Unión Europea. VIII. CONCLUSIÓN: ¿SE PUEDE GOBERNAR CON UN PARLAMENTO FRAGMENTADO? 


\title{
UN NUEVO PARLAMENTO FRAGMENTADO PARA LOS 40 AÑOS DE LA CONSTITUCIÓN
}

\author{
PIEDAD GARCÍA-ESCUDERO MÁRQUEZ ${ }^{1}$ \\ Catedrática de Derecho Constitucional \\ Universidad Complutense de Madrid
}

\section{INTRODUCCIÓN}

Son de todos conocidas las circunstancias políticas que han llevado a la configuración actual del Congreso de los Diputados. Tras un primer resultado electoral que no genera una mayoría que permita la investidura de Presidente del Gobierno, la brevísima XI Legislatura se cierra con las primeras elecciones convocadas en aplicación del artículo 99.5 de la Constitución, celebradas el 26 de junio de $2016^{2}$.

Levemente variada la composición del Congreso, un comienzo de legislatura a ritmo lento con investidura fallida incluída conduce finalmente a una investidura in extremis el 29 de octubre de 2016, que pone fin a un larguísimo periodo de gobierno en funciones ${ }^{3}$.

Numerosas cuestiones inéditas se han suscitado en estos últimos años del cuarto decenio de la Constitución, que han precisado de interpretaciones y aplicaciones también nuevas, estirando las costuras de un texto que hasta entonces resolvía sin problemas la sucesión de actos (disolución anticipada, elecciones e investidura) que

\footnotetext{
${ }^{1}$ Departamento de Derecho Constitucional. Facultad de Derecho. Universidad Complutense de Madrid. Ciudad Universitaria, s/n. 28040 Madrid. Email: piedadga@pdi.ucm.es

${ }^{2}$ El desarrollo de la XI y los inicios de la XII legislatura hasta llegar a la investidura pueden verse en P. García-Escudero Márquez, «Actividad legislativa del Parlamento con un Gobierno en funciones», en E. Aranda Alvarez (coord.), Lecciones constitucionales de 314 días con el Gobierno en funciones, Tirant lo Blanch, Valencia, 2017, págs. 237 y ss.

${ }^{3}$ Para la problemática planteada por el dilatado período de gobierno en funciones, véase P. García-Escudero Márquez, "Gobierno en funciones y función legislativa», Cuadernos Manuel Giménez Abad, n. ${ }^{\circ} 11$, págs. 106 y ss., así como M. Carrillo, «Las atribuciones del Gobierno en funciones», Revista Española de Derecho Constitucional, n. ${ }^{\circ} 109,2017$, págs. 121 y ss.
} 
marcan el paso de una legislatura a otra, con la posibilidad democráticamente impecable de una alternancia en el poder ${ }^{4}$.

El fin del bipartidismo que permitía gobernar por mayoría suficiente a uno de los dos grandes partidos PP y PSOE, apoyándose en su caso en pactos con las minorías nacionalistas, es hoy historia, quien sabe si sin retorno'.

El inicio de la XII legislatura, marcada por la problemática de la investidura y la polémica sobre el control del Gobierno en funciones que había llegado hasta el Tribunal Constitucional ${ }^{6}$, ha dejado en segundo plano lo que la nueva composición del Congreso de los Diputados ${ }^{7}$ - y su relación con un Senado en que el Partido Popular cuenta con una mayoría absoluta abrumadora ${ }^{8}$ - va a suponer para la actividad de nuestras Cortes Generales. De un Congreso cuasibipartidista, que apoya a un Gobierno identificado con una mayoría absoluta o suficiente, hemos pasado a una Cámara fragmentada, como muchos Parlamentos autonómicos tras sus últimas elecciones ${ }^{9}$, lo que afecta de forma evidente no sólo a su funcionamiento, sino al desempeño de las funciones constitucionales de las Cortes Generales.

En este trabajo apuntaremos sólo algunas cuestiones suscitadas en los dos primeros periodos de sesiones de la legislatura ${ }^{10}$, demostrativas de que nos hallamos ante un nuevo Congreso de los Diputados, muy distinto al de evolución pacífica o crecimiento sosegado que hemos conocido durante casi cuarenta años de vigencia de la Constitución.

4 En gráfica expresión de R. Blanco Valdés, pasamos del bipartidismo imperfecto a la perfecta ingobernabilidad ( «El año que vivimos peligrosamente: del bipartidismo imperfecto a la perfecta ingobernabilidad», Revista Española de Derecho Constitucional, n. ${ }^{\circ} 109,2017$, págs. 63 y ss.): la gobernabilidad ha sido una de las señas de identidad de la política española posconstitucional, la estabilidad, más que ninguna otra, ha sido la característica definidora de la política española desde el final de la transición (pág. 66).

5 La evolución electoral a partir de 2011, en P. García-Escudero Márquez, «Gobierno en funciones y función legislativa», cit., págs. 102 y ss.

${ }^{6}$ En la XI legislatura, el Congreso de los Diputados aprueba el planteamiento de un conflicto entre órganos constitucionales el 6 de abril de 2016 (Diario de Sesiones n. ${ }^{\circ}$ 7), como consecuencia de la no comparecencia en comisión del Ministro de Defensa en funciones. La propuesta había sido formulada por todos los grupos parlamentarios, salvo el Popular. El desarrollo de esta confrontación puede verse en P. García-Escudero Márquez, «Gobierno en funciones y función legislativa», cit., pág. 107.

7 Grupo Parlamentario Popular, 134 diputados; Socialista, 84; Confederal Unidos Podemos-En Comú podem-En Marea, 67; Ciudadanos, 32; Esquerra Republicana, 9; Vasco (EAJ-PNV), 5; Mixto, 19, entre ellos 8 del Partit Democrata de Catalunya y 4 de Compromìs.

${ }^{8}$ De un total de 266 senadores, el Grupo Popular cuenta con 149, más del doble que el siguiente, Socialista (62); GC UP-EC-EM, 20; GP Esquerra Republicana, 12; GP Vasco (EAJ-PNV), 6; Grupo Mixto, 17, de los que 4 pertenecen a CDC, 3 a Ciudadanos y 2 a Compromís.

9 Sobre las novedades que introduce la nueva composición fragmentada de los Parlamentos autonómicos pueden verse las ponencias de D. Parra y C. Ortega en el XV Congreso de la Asociación de Constitucionalistas de España (www.acoes.es), que serán publicadas en las Actas del Congreso (en prensa).

${ }_{10}$ Hasta el 30 de junio de 2017, en comparación con los dos primeros periodos de la X legislatura, año 2012. En curso de publicación, se han actualizado datos a 31 de diciembre de 2017. 


\section{EL FIN DEL BIPARTIDISMO NO SE REFLEJA SÓLO EN EL PLENO DE LA CÁMARA Y EN LAS COMISIONES}

La nueva composición del Congreso de los Diputados no afecta sólo al Pleno de la Cámara y a las comisiones constituidas a su semejanza (como también la Diputación Permanente), todos ellos órganos de trabajo que expresan la voluntad de la Cámara a través de las votaciones.

En efecto, una de las novedades que más incide en el funcionamiento del Congreso y en el ejercicio de sus funciones es que en la XII legislatura el grupo parlamentario del partido del Gobierno no cuenta con mayoría en los órganos de gobierno: Mesa de la Cámara, Presidencia y Mesa de las Comisiones.

\section{Mesa del Congreso de los Diputados}

La Mesa del Congreso de los Diputados, fruto de un pacto entre los grupos Popular, Socialista y Ciudadanos, tiene la siguiente composición: Presidencia, GPP; 4 Vicepresidencias: GPCs, GS, GPP y GUP-EC-EM; 4 Secretarías: GPP, GS, GUPEC-EM y GPCs.

Esto significa que el Grupo Popular — grupo minoritario más numeroso que apoya al Gobierno - tiene tres miembros en un órgano de nueve, de modo que sólo tendrá mayoría cuando le secunden los miembros de Ciudadanos o del Grupo Socialista.

La composición de la Mesa de la Cámara no es asunto baladí, de ahí que forme parte de los pactos políticos a negociar al inicio la legislatura. Hasta ahora, los dos grandes partidos, PP y PSOE, dado el sistema de voto mayoritario limitado establecido en el Reglamento para su elección, podían hacerse con todos los puestos en la Mesa, pero cedían algunos a las minorías, sobre todo el grupo en la oposición, pero también el de gobierno cuando no disponía de mayoría en la Cámara y necesitaba el apoyo de una minoría nacionalista para gobernar. En tales casos, el acuerdo de cesión incluía, no obstante, asegurarse el voto concordante en la Mesa a lo largo de la legislatura.

Rotos estos esquemas, los acuerdos de la Mesa del Congreso dejan de presentar un resultado previsible, lo que cobra particular importancia en el ejercicio de la competencia que reconoce a este órgano el artículo 31.1.4. ${ }^{\circ}$ del Reglamento del Congreso (RC) para «calificar, con arreglo al Reglamento, los escritos y documentos de índole parlamentaria, así como declarar la admisibilidad o la inadmisibilidad de los mismos».

Ninguna iniciativa se tramitará en la Cámara si no ha sido admitida por la Mesa en ejercicio de esta competencia. Si bien para determinar la admisión o inadmisión, la Mesa ha de regirse por criterios jurídicos («con arreglo al Reglamento»), es obvio que en asuntos conflictivos la interpretación que se haga del Reglamento no será unánime, siendo la mayoría que se forme en cada caso la que determine el sentido del acuerdo. 
Por poner sólo un ejemplo de lo que implica la falta de una mayoría favorable al Gobierno, la Mesa ha rechazado en el periodo examinado dos escritos de disconformidad del Gobierno con la tramitación de proposiciones de ley que suponen aumento de gasto o disminución de ingresos — formulada al amparo del artículo 134.6 de la Constitución - por entender que el Gobierno no justifica de forma objetiva y suficiente que las proposiciones impliquen aumento de créditos o disminución de ingresos del presupuesto en vigor ${ }^{11}$. Estas negativas han sido objeto de conflicto entre órganos constitucionales ante el Tribunal Constitucional ${ }^{12}$, en una situación inédita en el periodo de vigencia de nuestra Constitución.

En otro sentido, pero fruto de la misma falta de mayoría, se aprecia en la XII legislatura la utilización de la ampliación indefinida de los plazos de enmiendas a proposiciones de ley tomadas en consideración (hasta fines de 2017, presentadas 161, han sido tomadas en consideración $39^{13}$ ), como medio de detener o ralentizar su tramitación, siempre que para ello concurran los votos de los miembros de PP y Cs en la Mesa del Congreso.

\section{Presidencia y Mesa de las Comisiones}

En el sistema bipartidista hasta hace poco dominante, el uso parlamentario venía reservando las presidencias de algunas Comisiones del Congreso al principal grupo de la oposición (Presupuestos, Mixta para la Unión Europea por delegación del Presidente del Congreso, de Control de RTVE — hoy de Control Parlamentario de la Corporación RTVE_-) y algunas simbólicas, sobre todo especiales (como excepción, la Comisión de Asuntos Exteriores a CiU de la VIII a la X legislaturas), a algún otro grupo, especialmente si se requería su apoyo en la legislatura ${ }^{14}$.

11 Además, la Mesa ha acordado solicitar al Gobierno una mayor información en relación con la argumentación que avalaría su criterio contrario a la tramitación de la iniciativa en otros seis casos.

12 Conflicto entre órganos constitucionales n. ${ }^{\circ}$ 355-2017 y 356-2017, en relación con sendos Acuerdos de la Mesa del Congreso de los Diputados de 18 de octubre de 2016, ratificados el 20 de diciembre de 2016, por el que, rechazando la disconformidad expresada por el Gobierno, se toma en consideración para su tramitación por el Pleno la Proposición de ley orgánica presentada por el Grupo Parlamentario Socialista sobre la suspensión del calendario de la implantación de la Ley Orgánica 8/2013, de 9 de diciembre, para la mejora de la calidad educativa (LOMCE) y la Proposición de ley presentada por el Grupo Parlamentario Socialista sobre modificación del artículo 42.1 del Estatuto de los Trabajadores para garantizar la igualdad en las condiciones laborales de los trabajadores subcontratados, respectivamente. Admisión a trámite por el Tribunal Constitucional publicada en $B O E$ n. ${ }^{\circ} 45$, 22 febrero 2017. Las proposiciones de ley fueron tomadas en consideración por el Pleno del Congreso el 15 de noviembre y el 20 de diciembre de 2016, respectivamente.

${ }^{13}$ Número muy elevado, si se tiene en cuenta que se incluyen cada mes en el orden del día de las sesiones plenarias, en periodo ordinario, cinco proposiciones de ley de origen parlamentario.

14 En la X legislatura, Pacto de Toledo (GS), Seguridad Vial y Movilidad Sostenible (CiU), Cambio Climático $(\mathrm{GV})$. 
En la actual XII legislatura, también en este caso el esquema anterior se sustituye por un mosaico multicolor de presidencias en las que predominan los Grupos Popular y Socialista, muñidores del pacto, pero dando cabida a otros grupos: en las comisiones permanentes legislativas, el GPP cuenta con 8 presidencias $^{15}$; el GS con 6; GCUP-EC-EM, 2 ${ }^{16}$; Cs, 2; GMx PdeCat, $1^{17}$. A los grupos minoritarios se adjudican también comisiones especiales de particular significado, como la Comisión de Calidad Democrática, contra la corrupción y reformas institucionales y legales (Cs) y las de investigación, atribuidas tradicionalmente a partidos que no fueran los dos mayores, uso que se sigue manteniendo (GV, GMx Nueva Canarias, GMx Coalición Canaria) ${ }^{18}$. En cuanto a las Comisiones Mixtas, el GPP se reserva 4 (Tribunal de Cuentas, RTVE — frente al uso antes expuesto—- Seguridad Nacional y Drogas, correspondiendo al GS 1 (Unión Europea) y al GV 1 (Defensor del Pueblo).

Si las presidencias de las comisiones son importantes, pues actúan como elemento motor y moderador de las mismas, tal vez lo sea aún más el contar con mayoría en la Mesa de aquéllas, en particular por ser el órgano al que corresponde acordar el orden del día de la comisión, conforme al artículo 67.2 del Reglamento.

A diferencia de lo que ocurría en otras épocas ${ }^{19}$, en la legislatura en curso el grupo que apoya al Gobierno no dispone de la mayoría de los cinco miembros que componen la Mesa de las comisiones, siéndole necesario para alcanzarla el voto de Cs en 2 comisiones permanentes legislativas (Constitucional, Empleo), o del GS en 10 (Asuntos Exteriores, Justicia, Interior, Defensa, Fomento, Educación, Energía, Agricultura, Sanidad, Cambio Climático), de uno u otro grupo en 3 (Economía, Hacienda, Presupuestos). La Mesa de otras 4 comisiones está integrada por un miembro de distintos grupos parlamentarios.

Las comisiones permanentes legislativas no sólo son el órgano preparatorio de los trabajos del pleno en materia legislativa, al que en ocasiones sustituyen cuando actúan con competencia legislativa plena, sino el órgano ordinario de control de la actuación de los departamentos ministeriales y de sus titulares, estos últimos sobre todo mediante comparecencias ante la comisión.

15 Además de las presidencias que le corresponden en comisiones no legislativas por disposición reglamentaria (Reglamento, Estatuto de los diputados y Peticiones), a las que se suman dos permanentes no legislativas.

${ }^{16}$ UP-EC-EM cuenta además con la Presidencia de la Comisión permanente no legislativa de Derechos de la Infancia y adolescencia.

17 Si buscamos la ratio número de diputados del Grupo/presidencia de comisión, vemos una clara infrarrepresentación de UP-EC-EM, que no formó parte del pacto inicial: GPP, 1 comisión por 16 diputados; GS, 14; UP, 33; Cs, 16, Mx, 19.

${ }_{18}$ Comisiones de investigación constituidas en el primer periodo de sesiones de 2017: de utilización partidista del Ministerio del Interior; sobre la crisis financiera de España y programa de asistencia; sobre la presunta financiación ilegal del Partido Popular.

${ }_{19}$ Los cinco miembros se distribuían habitualmente entre el grupo mayoritario (3) y el principal grupo de la oposición (2), al menos en las comisiones permanentes legislativas. 
Un ejemplo de las disfunciones que para el Gobierno puede significar no contar con una Mesa favorable en las comisiones es la introducción, en el orden del día de una sesión de comisión, de asuntos contra su voluntad: solicitudes de comparecencia en materias incómodas, que suelen dar lugar a que el Ministro se pliegue, presentando su asistencia como a petición propia; o iniciativas legislativas cuya tramitación el Ejecutivo no tiene interés en acelerar.

\section{EL ESTATUTO DE LOS DIPUTADOS}

La nueva composición de la Cámara se refleja también en el aumento de iniciativas de reforma del Reglamento del Congreso de los Diputados (RC), 7 en el primer año de legislatura.

Pero como muestra de lo que los nuevos tiempos aportan en relación con el estatuto de los diputados, nos referiremos a las vicisitudes del primer dictamen de la Comisión de incompatibilidades, en el que se revisan las declaraciones de actividades que los diputados deben cumplimentar para adquirir su condición plena, conforme al artículo $20 \mathrm{RC}$, para comprobar que no se incurre en las incompatibilidades establecidas por la Ley Orgánica 5/1985, de 29 de junio, del Régimen Electoral General.

Este dictamen, emitido por la Comisión del Estatuto de los Diputados el 23 de febrero, se aprueba por el Pleno un año después de las elecciones, el 29 de junio de 2017, tras haber sido excluido del orden del día de la sesión plenaria de 9 de marzo. El origen del retraso, como se expone en el Diario de Sesiones del debate de aprobación, se encuentra en la oposición del Grupo Socialista a autorizar determinadas actividades permitidas por la ley a 38 diputados, frente a la postura de los restantes grupos parlamentarios. Cuando se preveía que el dictamen iba a votarse separadamente para cada diputado al que afectaba, la aprobación se solventa con la abstención del Grupo Socialista sobre el conjunto del dictamen, por tanto incluso sobre el dictamen favorable respecto de sus propios diputados.

En suma, lo que hasta ahora era un trámite que planteaba problemas sólo respecto de un puñado de diputados, que debían resolver su situación antes de ser incluidos en el dictamen, se convierte en un objeto de debate político.

\section{LA FUNCIÓN LEGISLATIVA: ¿PUEDE UN GOBIERNO GOBERNAR SIN LEGISLAR?}

\section{Iniciativa legislativa}

Durante un largo período de gobierno en funciones, que abarcó incluso la XI legislatura completa — bien es verdad que de corta duración, apenas seis meses — al 
Gobierno le estaba vedado, por imperativo legal ${ }^{20}$, presentar proyectos de ley. Durante ese período, en las legislaturas XI y XII, los grupos parlamentarios de oposición fueron muy activos en la presentación de proposiciones de ley ${ }^{21}$. Las presentadas en la legislatura breve caducaron todas ellas, sin que llegara a aprobarse ninguna ley.

Por el contrario, durante el período de gobierno en funciones en la XII legislatura, dos proposiciones de ley presentadas por el Grupo Popular (necesariamente, pues no podían presentarse como proyectos) llegan a convertirse en leyes ${ }^{22}$. Es también en este período cuando se agudiza el desencuentro Congreso-Gobierno en funciones, que ya había dado lugar en la anterior legislatura a un conflicto entre órganos constitucionales en materia de control, para suscitarse esta vez en relación con la tramitación de proposiciones de ley que suponen aumento de gastos o disminución de ingresos presupuestarios. Como se ha señalado, admitidas a trámite de toma en consideración dos de ellas en contra del criterio del Gobierno, una vez producida la investidura y previo requerimiento del Consejo de Ministros, el Gobierno plantea sendos conflictos entre órganos constitucionales ante el Tribunal Constitucional ${ }^{23}$.

El mayor uso por el Gobierno, no sólo en funciones sino a lo largo de la legislatura $^{24}$, de las facultades que le reconoce el artículo 134.6 de la Constitución para oponerse a la tramitación de proposiciones de ley ha de conectarse con la falta de mayoría en el Pleno, que le impedirá cerrar al paso a las proposiciones en el trámite de toma en consideración.

Entrados en una supuesta senda de normalidad parlamentaria a partir de la investidura, al recuperar el Gobierno sus facultades de iniciativa legislativa, nos encontramos no obstante con un panorama inusual.

De una parte, el Gobierno se piensa muy mucho qué proyectos de ley envía al Congreso de los Diputados, pues no está seguro de su aprobación como ley y de los términos de la misma, tras la tramitación parlamentaria.

${ }^{20}$ Art. 21.5 Ley 50/1997, de 27 de noviembre, del Gobierno.

${ }^{21}$ Un análisis y datos de esta situación, en P. García-Escudero Márquez, «Actividad legislativa del Parlamento con un Gobierno en funciones», cit. Véase también I. M. Giménez Sánchez, «La actividad desarrollada por las Cortes en la situación de legislatura fallida y de Gobierno en funciones», Revista Española de Derecho Constitucional n. ${ }^{\circ}$ 109, 2017, págs. 215 y ss.

${ }^{22}$ Ley Orgánica 1/2016, de 31 de octubre, de reforma de la Ley Orgánica 2/2012, de 27 de abril, de Estabilidad Presupuestaria y Sostenibilidad Financiera y Ley Orgánica 2/2016, de 31 de octubre, de modificación de la Ley Orgánica 5/1985, de 19 de junio, del Régimen Electoral General, para el supuesto de convocatoria automática de elecciones en virtud de lo dispuesto en el apartado 5 del artículo 99 de la Constitución. Las proposiciones de ley del GPP fueron tomadas en consideración el 18 de octubre, la primera por 258 votos a favor, 18 en contra y 66 abstenciones, la segunda por 340 votos a favor, la unanimidad de los votos emitidos.

${ }^{23}$ Véase supra, nota 12.

${ }^{24}$ En función del voto de los distintos miembros de la Mesa de la Cámara, otros de estos mal llamados «vetos presupuestarios» del Gobierno son aceptados. Pueden verse ejemplos en BOCG Serie B n. ${ }^{\circ} 92-2$, de 5 de mayo de 2017, y 116-2, 118-2, 119-2, 120-2, 123-2 y 126-2, de 30 de junio de 2017. Expresada por el Gobierno su disconformidad, la Mesa acuerda que no procede la toma en consideración por el Pleno de la proposición de ley. 
De otra parte, se multiplican las proposiciones de ley de iniciativa parlamentaria (161 hasta fines de 2017) y, sobre todo, se toman en consideración indiscriminadamente (39 en el mismo periodo), aunque su tramitación no se inicia de inmediato, porque no está tan claro que los grupos que apoyaron ese trámite inicial deseen la conversión en ley de la iniciativa. Es aquí el juego de mayorías en la Mesa, fundamentalmente el acuerdo PP-Cs a que se ha aludido ya, el que permite ampliar indefinidamente el plazo de enmiendas. Incluso después de concluido éste, tampoco avanza la tramitación, pese a los esfuerzos del grupo proponente, cuando los restantes carecen de interés en la iniciativa.

Las cifras son elocuentes: a 30 de junio de 2017, transcurridos dos periodos ordinarios de sesiones completos de legislatura, el Gobierno — titular de la iniciativa prioritaria y prevalente, que antaño presentaba el 90 por ciento de las iniciativas legislativas, el 90 por ciento de las cuales se convertían en ley- había presentado 8 proyectos de ley, entre ellos el de Presupuestos Generales del Estado para 2017 y los restantes — salvo uno- de transposición de directivas o cumplimiento de reglamentos europeos, de los cuales se convirtieron en ley sólo dos ${ }^{25}$, el de presupuestos y otro ${ }^{26}$. A la misma fecha de cierre de período de sesiones ordinario, son 116 las proposiciones de ley de Grupos parlamentarios presentadas y calificadas (2 más sin calificar), y 22 las tomadas en consideración. Además de las dos tramitadas y aprobadas como ley durante el periodo de gobierno en funciones, otras dos se han convertido en ley ${ }^{27}$.

Ante esta autorrepresión de la iniciativa legislativa del Gobierno (que de no autolimitarse probablemente vería sus textos también rechazados o desfigurados a lo largo de la tramitación), se nos plantea la pregunta que ya nos habíamos hecho respecto del gobierno en funciones en un periodo inusualmente prolongado: ¿puede el Gobierno gobernar sin legislar?

A esta pregunta responde Aragón Reyes con una «conclusión esperanzada» ${ }^{28}$ : un Gobierno minoritario no tiene por qué significar un Gobierno inestable e ineficaz, sino un Gobierno que ha de pactar en las Cámaras. Pero una oposición mayoritaria

25 A estos proyectos han de sumarse 2 decretos-leyes tramitados como proyectos de ley una vez convalidados, en junio de 2017, que no pueden considerarse propiamente iniciativas legislativas del Ejecutivo.

26 Proyecto de Ley sobre restitución de bienes culturales que hayan salido de forma ilegal del territorio español o de otro Estado miembro de la Unión Europea, por la que se incorpora al ordenamiento español la Directiva 2014/60/UE, del Parlamento Europeo y del Consejo de 15 de mayo de 2014.

${ }^{27}$ Comparemos las cifras con los dos primeros períodos de sesiones de la X legislatura, aunque se tratara de un supuesto algo anómalo por estar España inmersa en una crisis económica que favorecía el gobierno por decreto-ley: 8 leyes orgánicas y 17 leyes ordinarias en 2012. Una comparativa del número de leyes y decretos leyes de 2012 a 2015, en P. García-Escudero Márquez, «Regeneración del Parlamento, transparencia y participación ciudadana», Teoría y Realidad Constitucional, n. . 36, 2015, pág. 181. El número de leyes aprobadas por las Cortes Generales en el año 2017 es de 12 ordinarias y 1 orgánica, 8 de ellas fruto de proyectos del Gobierno (de las cuales 5 para la transposición de directivas europeas, 2 en relación con el concierto y cupo vasco, y la Ley de Presupuestos Generales del Estado para 2017).

28 M. Aragón Reyes, «Legislatura fallida e investidura convulsa. Análisis y consecuencias», Revista Española de Derecho Constitucional, n. ${ }^{\circ}$ 109, 2017, pág. 33. 
tampoco debe significar una constante obstrucción de la tarea del Gobierno. Un Gobierno minoritario sin tales pactos sería incapaz de gobernar ${ }^{29}$. En todo caso, el autor citado advierte frente a una deriva hacia un parlamentarismo de asamblea, que directamente destruye el régimen parlamentario, en el que debe existir una reserva de Gobierno (dirigir la política) y una reserva de Parlamento (controlar aquélla).

\section{Intentos de suplir la falta de iniciativa}

Veamos dos pasos que se han dado en direcciones opuestas, como ejemplos de las dos advertencias de Aragón:

a) Las subcomisiones como medio de consensuar iniciativas legislativas

Si el Gobierno no puede enviar al Congreso proyectos de ley porque no está seguro de su resultado, se intentará pactar el contenido de las leyes mediante la creación de subcomisiones en las comisiones permanentes legislativas, constituidas a iniciativa de distintos grupos. Así nos encontramos a 30 de junio de 2017 con siete subcomisiones creadas en las comisiones permanentes legislativas del Congreso sobre temas que habrían de conducir a sendas iniciativas legislativas consensuadas: reforma electoral, estrategia nacional de la justicia, régimen profesional de los militares de las Fuerzas Armadas, pacto Estado social y político por la educación, reforma del régimen especial de trabajadores por cuenta propia o autónomos RETA, Estatuto del Artista, pacto de Estado en materia de violencia de género... ${ }^{30}$.

Estas subcomisiones se añaden a las comisiones especiales, de estudio o investigación (de las que también podrían resultar propuestas legislativas), e incluso a las que deberían ser comisiones permanentes no legislativas de estudio porque no se corresponden con departamentos ministeriales, pero que — novedad también de los nuevos tiempos — se dotan de carácter legislativo: no sólo Cooperación internacional para el desarrollo e Igualdad, que ya tenían este carácter en la X legislatura, sino también Cambio climático y Políticas integrales de la discapacidad.

29 A diferencia de los Gobiernos autonómicos en minoría, donde no tiene que ser necesariamente así, dado que sus competencias no son tan determinantes para los intereses generales como las que posee el Gobierno estatal. M. Aragón Reyes, ibidem.

30 Además de la Subcomisión creada en una comisión especial citada en nota 37 y de dos ponencias de estudio. Un acuerdo de la Mesa del Congreso de 20 de septiembre de 2016 limitaba el número de subcomisiones que podían existir simultáneamente a 6 . Por acuerdo de 13 de diciembre de 2016, se eleva este número a 8 . Piénsese en lo que supone para los grupos de menor tamaño el funcionamiento simultáneo de este número de subcomisiones, junto a las 19 comisiones permanentes legislativas, 7 permanentes no legislativas, 3 comisiones de investigación y 6 comisiones mixtas permanentes. Al finalizar 2017, sólo la Subcomisión sobre el Pacto de Estado en materia de violencia de género había concluido sus trabajos mediante la aprobación — a la que no se sumó UP_ y elevación de su informe a la Comisión de Igualdad y posteriormente al Pleno de la Cámara. 
b) El procedimiento de lectura única para textos no tan sencillos ni unánimes

El artículo $150 \mathrm{RC}$ reserva el procedimiento especial de lectura única para la tramitación de los proyectos o proposiciones de ley cuya naturaleza lo aconseje o la simplicidad de formulación lo permita. De hecho, se suele recurrir a este procedimiento cuando existe un consenso tal sobre el contenido que hace prever que el texto no será variado en el curso de la tramitación o cuando recae acuerdo unánime de tramitación acelerada por urgencia política en la promulgación de la ley ${ }^{31}$.

Sin embargo, en los inicios de la XII legislatura objeto de nuestro análisis encontramos ejemplos que no encajan ni en el texto reglamentario ni en los usos, y que más bien parecen augurar el parlamentarismo de asamblea a que alude Aragón Reyes.

Se utilizaría este procedimiento abreviado para iniciativas no siempre tan sencillas que, en definitiva, pretenden deshacer la obra legislativa del Gobierno anterior, con la particularidad de que coincide en color con el actual, o dicho de otra manera, con la obra del Gobierno actual cuando era anterior, pues el Presidente continúa siendo el mismo ${ }^{32}$.

Así ocurre con la Proposición de Ley de modificación de la Ley 1/1996, de 10 de enero, de asistencia jurídica gratuita. Las enmiendas formuladas y la aprobación no unánime revelan que el texto no es plenamente compartido, aunque lo fuera la necesidad de legislar ${ }^{33}$.

El ejemplo más claro de utilización del procedimiento de lectura única para la tramitación de una iniciativa compleja y no unánime es la Proposición de Ley del Grupo Socialista sobre la modificación de la Ley 17/2006, de 5 de junio, de la radio y la televisión de titularidad estatal, para recuperar la independencia de la Corporación RTVE y el pluralismo en la elección parlamentaria de sus órganos (dirigida a anular la reforma introducida por el Real Decreto-ley 15/2012, de 20 de abril, de modificación del régimen de administración de la Corporación RTVE, previsto en la Ley 17/2006, de 5 de junio, requiriendo de nuevo la mayoría de dos tercios en ambas Cámaras para el nombramiento de los miembros del Consejo de Administración). Se

31 Además de aquellos proyectos que introducen un elemento pactista en su elaboración. Véase P. García-Escudero Márquez, El procedimiento legislativo ordinario en las Cortes Generales, Centro de Estudios Políticos y Constitucionales, Madrid, 2006, págs. 113-114.

32 Ejemplos de proposiciones sencillas tendentes a deshacer la obra legislativa anterior frente a un Gobierno continuista, aunque no se tramiten por lectura única, son —entre otras — la Proposición de Ley Orgánica de modificación de la Ley Orgánica 10/1995, de 23 de noviembre, del Código Penal, con la que se trata de eliminar la pena agravada impuesta a los piquetes informativos «violentos» por el artículo 315.3 del Código Penal tras la reforma introducida por Ley Orgánica 1/2015, de 30 de marzo, eliminación solicitada, tras las primeras condenas, por los sindicatos mayoritarios y los partidos políticos afines a los mismos; y la Proposición de Ley de derogación del plazo máximo previsto para la instrucción en la Ley de Enjuiciamiento Criminal, plazo introducido por la Ley 41/2015, de 5 de octubre.

33 No fue unánime el resultado de la votación en lectura única en el Congreso, como tampoco lo fue el de tramitación por este procedimiento, con 65 votos en contra y 6 abstenciones y 69 en contra y 1 abstención, respectivamente. 
trataba de una reforma de no tan sencilla formulación, como lo demuestra el número y envergadura de las enmiendas presentadas, en la que el propio Grupo Popular votó a favor de la tramitación por lectura única para no quedarse en solitario.

Más aún, la utilización del procedimiento de lectura única en un texto sin acuerdo y complejo provocó que en la aprobación por el Pleno del Congreso el 22 de junio de 2017 se produjeran varios empates y la incorporación de enmiendas incongruentes entre sí, como las relativas al número de miembros del Consejo de Administración de RTVE $^{34}$.

\section{El procedimiento legislativo en Comisión. La ponderación de voto en las ponencias}

La nueva composición de la Cámara plantea numerosos incidentes en el procedimiento legislativo, desvelando insuficiencias en la consuetudinaria aplicación del Reglamento o en las prácticas acuñadas. Pensemos simplemente en la mayor complejidad de las votaciones, en las que el sentido del voto de cuatro partidos determina resultados variables, frente a los previsibles cuando sólo dos eran los partidos determinantes.

Nos centraremos en un ejemplo de las nuevas situaciones, referido a las ponencias, órgano de trabajo de las comisiones de gran relevancia en el procedimiento legislativo, pues el informe resultado de su trabajo permite presagiar el texto de la futura ley.

A diferencia de las comisiones, las ponencias no reflejan la composición del Pleno, pero para que su labor sea de utilidad, y que el informe en el que proponen la incorporación de enmiendas al texto del proyecto o de la proposición sea aceptable para la comisión, han venido actuando con voto ponderado en el periodo de vigencia de nuestra Constitución. A partir de la modificación introducida por la Resolución de la Presidencia de 18 de mayo de 2004 (al comienzo de la VIII legislatura) en la Resolución de 23 de septiembre de 1986, sobre designación y funciones de las ponencias, se incorpora a ésta el inciso siguiente: «en el caso de producirse votación, se aplicará el criterio de voto ponderado» ${ }^{35}$.

34 Diario de sesiones n. ${ }^{\circ}$ 64, de 22 de junio de 2017. Dado que el Grupo Popular cuenta en el Senado con mayoría absoluta, podía resolver la incongruencia mediante enmiendas o dejarla en sus términos, de forma que sería inaplicable el nuevo sistema de nombramiento hasta tanto otra ley modificara las contradicciones introducidas en la ley, lo que retrasaría la instauración del nuevo sistema de elección. Aprobada la Ley 15/2017, resurge la falta de acuerdo inmediatamente, impidiendo la aprobación, en el plazo de tres meses establecido por la ley, de la normativa necesaria para poner en marcha la selección de candidatos por las Cortes Generales, previo concurso público con la participación de un Comité de expertos.

${ }^{35} \mathrm{La}$ adopción de acuerdos mediante voto ponderado se había establecido ya en el Senado por Norma interpretativa de la Presidencia de 18 de noviembre de 1997. Sobre la evolución que lleva a la «legalización» reglamentaria del voto ponderado y la problemática que plantea su relación con el artículo $79.3 \mathrm{CE}$, según el cual el voto de senadores y diputados es personal e indelegable, puede verse P. García-Escudero Márquez, El procedimiento legislativo ordinario en las Cortes Generales, cit., págs. 353 y ss. 
Al inicio de la XII legislatura ${ }^{36}$, por Resolución de la Presidencia del Congreso de los Diputados de 13 de diciembre de 2016 (BOCG Congreso, Serie D, n. ${ }^{\circ}$, de 16 de diciembre), se modifica la Resolución de 1986 para adecuar las ponencias a la nueva composición, en la forma siguiente: 3 GPP; 2 GS, UP-EC-EM y Cs; 1 ER y GV; 2 GMx. Hasta ahora, se adjudicaba al Grupo Mixto un solo miembro en las ponencias.

Como es sabido, el Grupo Mixto es un Grupo de carácter residual que, al menos al inicio de las legislaturas, se integra por los parlamentarios de fuerzas políticas de distinto signo que no han conseguido representación suficiente para formar un grupo propio. Si el Grupo Mixto cuenta con dos miembros en las ponencias y estos votan en sentido distinto, se plantea cómo ponderar el voto de este grupo.

En las Comisiones, para las que el artículo 88.2 RC establece el voto ponderado como medio de dirimir los empates cuando sea idéntico el sentido en el que hubieren votados todos los miembros de la comisión pertenecientes a un mismo grupo parlamentario, la disparidad de voto en el seno del Grupo Mixto no plantea problemas, pues en tal caso se aplica el régimen ordinario para los empates, previsto en el apartado 1 del citado artículo: repetición de la votación por dos veces y, si el empate persiste, se entiende desechada la iniciativa objeto de la votación.

Pero en las ponencias, el voto ponderado constituye su forma de adoptar acuerdos y no puede dejar de aplicarse, ni siquiera cuando los dos miembros del Grupo Mixto voten en sentido distinto. Este problema es compartido por aquellas subcomisiones y comisiones de investigación en las que al Grupo Mixto corresponden dos miembros (que no han sido todas las constituidas), porque también allí los acuerdos se adoptan por voto ponderado.

Para resolver la ponderación en caso de disparidad de voto en el seno del Grupo Mixto en subcomisiones y comisiones de investigación se ha acudido a distintos criterios:

- que prevalezca el voto del portavoz del Grupo Mixto en la comisión o en la subcomisión, y en su defecto el del portavoz adjunto ${ }^{37}$

- atribuir a cada uno de los votantes del Grupo Mixto los votos de los miembros con que este cuenta en el Pleno: 19:2=9.5. Este sistema ofrece la peculiaridad de dividir a un diputado (y su voto) por la mitad a efectos de cómputo (Comisión de investigación sobre la presunta financiación ilegal del Partido Popular)

36 En la XI legislatura, la Resolución de la Presidencia del Congreso de 5 de abril de 2016 atribuía un solo miembro al Grupo Mixto, y el Grupo Catalán (DyL) contaba asimismo con uno.

37 Subcomisión relativa al régimen y la financiación de los partidos políticos, la imparcialidad e independencia de autoridades independientes y la protección de los denunciantes de los casos de corrupción, creada en la Comisión para la auditoría de la calidad democrática, la lucha contra la corrupción y las reformas institucionales y legales. Véase BOCG Congreso, Serie D, n. ${ }^{\circ}$ 81, 5 enero 2016, pág. 6: «A los efectos de la ponderación del voto, cuando dos o más integrantes de un grupo parlamentario votaran en sentido discordante, únicamente se tendrá en cuenta el criterio expresado por el portavoz del citado grupo en la Comisión. En ausencia del portavoz, se tendrá en cuenta el criterio expresado por el portavoz adjunto. En todo caso, se reflejará en el acta de la sesión el sentido del voto indicado por cada Diputado». 
- atribuir a cada votante el porcentaje que corresponda a su formación política en el total del Grupo Mixto (Comisión de investigación sobre la crisis financiera de España)

En el caso de las Comisiones de investigación y subcomisiones, la disparidad de los criterios utilizados para la ponderación puede hallar justificación en el hecho de que las primeras fijan cada una sus propias normas de funcionamiento (aunque el Reglamento atribuye esta facultad a la Presidencia de la Cámara, oída la Comisión, art. 52.3) o de que en unas y otras estas normas figuran en el acuerdo de creación, aprobado por el Pleno a iniciativa de distintos grupos parlamentarios y con textos distintos.

Pero donde no cabe admitir disparidades de interpretación, por lógica, es en la aplicación de la Resolución antes citada por las ponencias legislativas constituidas en las 19 comisiones permanentes legislativas del Congreso, en las que el problema de la ponderación de los dos miembros discordantes del Grupo Mixto se plantea en toda su magnitud.

Para colmo de males, cuando por primera vez es necesario tomar una decisión al respecto es en la tramitación del Proyecto de Ley de Presupuestos Generales del Estado para 2017, a la que nos referiremos al tratar de la función presupuestaria, en la que se superaron las 6000 enmiendas presentadas y se multiplicaron las incidencias reglamentarias.

Como puede apreciarse en el Informe de la Ponencia designada para informar el Proyecto de Ley ${ }^{38}$ (para empezar, el GC UP-EC-EM anunció que no participaría en la votación, como consecuencia de otras decisiones de la Mesa de la Comisión a las que luego se aludirá), el voto de los miembros de la ponencia pertenecientes al Grupo Mixto fue computado por cabeza, esto es, uno por votante. Es decir, que respecto del Grupo Mixto no se aplicó la ponderación ${ }^{39}$.

Contra el acuerdo de la Mesa de la Comisión que decidió adoptar este criterio se presentó recurso ante la Mesa de la Cámara por los diputados de PDeCat y Compromís, 12 de los 19 componentes del Grupo Mixto. En este recurso se expone que la Mesa de la Comisión barajó los dos criterios anteriormente señalados utilizados en otras comisiones, otorgar el sentido al portavoz del grupo en la comisión o dar 9.5 a cada miembro, inclinándose por una tercera posibilidad, otorgar un voto a cada ponente del Grupo Mixto.

38 BOCG Congreso Serie A n. ${ }^{\circ}$ 6-10, pág. 2.

39 Consta en el informe que, una vez producida la primera votación, en la que los dos miembros del Mixto votaron de forma distinta, «una vez explicado al Sr. Bel Accensi del Grupo Mixto que la Mesa de la Comisión había decidido previamente que en caso de que los Diputados del Grupo Mixto presentes en la Ponencia votasen en sentido contrario, su voto no se ponderaría y se computaría como un solo voto por cada uno de los votantes, este manifestó su disconformidad y abandonó la ponencia». A partir de ahí, aunque sólo está presente y vota un miembro del Grupo Mixto, se continúa computando a este Grupo un único voto (BOCG Congreso n. ${ }^{\circ}$ A-6-10, de 24 de mayo de 2017). 
Por considerar que las tres opciones que barajó la Mesa de la Comisión no son las únicas posibles, los firmantes solicitaban de la Mesa de la Cámara que, para no vulnerar la imprescindible proporcionalidad de la Cámara, decidiera entre las siguientes opciones de ponderación:

— que al voto de cada miembro se le atribuya el $50 \%$ de los miembros del Grupo Mixto

- que el voto de cada ponente se limite a incorporar los votos de los diputados «a los que representa» (entendemos quiere decir a los miembros de su formación política en el Grupo Mixto, porque en realidad los ponentes representan al Grupo)

- que a cada ponente se le computen los votos de aquellos miembros que explícitamente se lo hayan otorgado; es decir, añadimos nosotros, que le hayan delegado su voto, lo que choca con la prescripción del artículo 79.3 de la Constitución, a la vez que incorpora un elemento iusprivatista que no debe aplicarse a una Cámara parlamentaria.

La Mesa del Congreso, en su reunión de 26 de mayo de 2017, acordó que no procedía acceder a la solicitud por no existir un sistema general de recursos contra los acuerdos de las Mesas de las comisiones. No obstante, continúa siendo necesario unificar para todas las comisiones la interpretación de la Resolución inicial sobre composición de las ponencias, para lo cual la solución más sencilla es la de otorgar un único miembro al Grupo Mixto en las mismas.

\section{El decreto-ley no constituye alternativa a la ley}

Mermado el Gobierno en su iniciativa legislativa por la incertidumbre sobre el resultado, la misma incertidumbre planea sobre el destino de los decretos-leyes y hace que el Gobierno sea cauto en su uso. Aprobados 11 Reales Decretos-leyes en el primer semestre de 2017, 2 de ellos responden a la necesidad de remediar, en materia de empleo, la no aprobación de los Presupuestos Generales del Estado y otros a atender necesidades sociales (deudores hipotecarios), daños por temporales o sequía (2), o compromisos internacionales o transposición de directivas $(4)^{40}$.

Todos ellos, salvo uno, fueron convalidados por el Congreso. La excepción la constituye el primer decreto-ley regulador del régimen de la estiba, Real Decreto-Ley $4 / 2017^{41}$, fruto de compromisos internacionales (cumplimiento de una sentencia del

${ }^{40}$ El último del semestre, Real Decreto-ley 11/2017, de 23 de junio, de medidas urgentes en materia financiera, fue convalidado en sesión extraordinaria el 10 de julio. En 2017 fueron 21 los decretos-leyes aprobados.

41 Real Decreto-ley 4/2017, de 24 de febrero, por el que se modifica el régimen de los trabajadores para la prestación del servicio portuario de manipulación de mercancías dando cumplimiento a la Sentencia del Tribunal de Justicia de la Unión Europea de 11 de diciembre de 2014, recaída en el asunto C-576/13 (procedimiento de infracción 2009/4052). BOE, núm. 48, de 25 de febrero de 2017. 
Tribunal de Justicia de la Unión Europea), como se desprende de su título, pero en un tema de profunda conflictividad laboral que propicia la oposición al Gobierno. Reformulado tras la no convalidación como Real Decreto-Ley 8/2017 con el mismo título y matices en su contenido, que deja fuera temas relevantes para el desarrollo reglamentario, es finalmente convalidado.

Para hallar un precedente de rechazo voluntario de la convalidación de un decreto-ley —que implica su inmediata derogación — hay que remontarse a $1979^{42}$. Existe otro supuesto de no convalidación por error en $2006^{43}$. Estos datos muestran cuán inusual es que, en nuestro régimen parlamentario, el Congreso no convalide un decreto-ley. Si en el caso que nos ocupa ello llegó a producirse, fue porque el Gobierno se veía impelido a aprobar la norma, aun sin estar seguro de su convalidación, para cumplir con una sentencia del TJUE y tratar de evitar las sanciones europeas. En otros supuestos de oposición parlamentaria esperada de antemano, salvo que exista alguna razón jurídica — como en este caso- o política para desear que dicha oposición se ponga de manifiesto en el trámite parlamentario, el Gobierno se abstendrá de legislar por decreto-ley: un segundo cauce, además del de los proyectos de ley, que si no se le cierra, sí deberá administrar con cuentagotas y no con la alegría de otras épocas.

En suma, en un año de legislatura, aparte de la Ley de Presupuestos Generales del Estado para 2017, tan sólo culminaron su tramitación otro proyecto y cuatro proposiciones de ley (dos de ellas en 2016, en periodo de gobierno en funciones) ${ }^{44}$ frente a las 8 leyes orgánicas y 17 ordinarias aprobadas en 2012, al inicio de la X legislatura iniciada con las elecciones de 20 de noviembre de $2011^{45}$.

42 Real Decreto-ley 1/1979. Acuerdo sobre derogación aprobado por la Diputación Permanente del Congreso de los Diputados de 6 de febrero de 1979, Diario de Sesiones n. ${ }^{\circ}$ 21, BOE 23 febrero 1979 .

43 Acuerdo sobre derogación del Real Decreto-Ley 1/2006, de 20 de enero, por el que se modifican los tipos impositivos del impuesto sobre las labores del tabaco, Pleno del Congreso de 9 de febrero de 2006, Diario de sesiones n. ${ }^{\circ}$ 148, BOE 11 febrero 2006. El Real Decreto-Ley 2/2006, que modifica levemente el título y parcialmente el contenido del anterior, fue convalidado el 23 de febrero de 2006. En el Diario de sesiones (n. ${ }^{\circ} 154$, pág. 7717), el portavoz del GPP alude al error en la votación de convalidación del decreto-ley anterior por parte del Grupo Socialista, que se dividió entre el sí y el no.

${ }^{4}$ En una sola de las iniciativas el Senado introdujo enmiendas, siendo necesaria la vuelta del texto al Congreso de los Diputados: Proposición de Ley de modificación de la Ley 15/2015, de 2 de julio, de Jurisdicción Voluntaria; se enmendaba para incluir la prórroga un año más de la entrada en vigor del Registro Civil electrónico. Como se ha señalado, durante el año 2017 se aprueban 13 leyes, una de ellas orgánica.

45 Bien es verdad que con un cambio de color del Gobierno, lo que supone un mayor impulso legislativo, y en una situación de crisis que reclamaba medidas legales. 


\section{LA FUNCIÓN PRESUPUESTARIA: EL PRESUPUESTO, VOTO A VOTO}

Podemos apuntar algunas diferencias que la primera tramitación de la Ley de Presupuestos Generales del Estado en la XII legislatura ha ofrecido con respecto a lo que venía siendo tradicional en los casi cuarenta años de Constitución, con algunas variaciones o mayores dificultades en los casos de Gobierno sin mayoría absoluta.

En primer lugar, pese a que las elecciones tienen lugar el 26 de junio de 2016 y la investidura del Presidente del Gobierno el 29 de octubre, el Proyecto de ley de Presupuestos Generales del Estado para el año 2017 no se aprueba y envía al Congreso hasta el 4 de abril de 2017. Por tanto, en este año habrían de tramitarse supuestamente dos presupuestos, uno en primavera y otro en otoño, circunstancia que sólo se producía cuando las elecciones tenían lugar en el último trimestre del año ${ }^{46}$.

Es decir, superado el plazo previsto en el artículo 134.2 de la Constitución («El Gobierno deberá presentar ante el Congreso de los Diputados los Presupuestos Generales del Estado al menos tres meses antes de la expiración de los del año anterior») sin que hubiera un Gobierno en plenitud de facultades, una vez en ejercicio no tiene prisas en presentar unos presupuestos de cuya aprobación no está seguro, y sólo lo hace cuando cree que puede llegar a los acuerdos necesarios ${ }^{47}$.

Acuerdos que son, como se indica en la rúbrica de este epígrafe, negociados paso a paso y voto a voto. Si 175 votos son necesarios para rechazar las enmiendas a la totalidad por empate ${ }^{48}, 175$ votos se conseguirán con el apoyo, aparte del GPP (134) y de Cs (32), de los diputados de UPN (2), Coalición Canaria (1), Grupo Vasco (5) y Foro (1).

Salvado este primer obstáculo, hace falta un voto más para aprobar el dictamen de la Comisión de Presupuestos. Al igual que con las anteriores negociaciones, la prensa va reflejando los avances que se producen con el diputado de Nueva Canarias (partido coaligado con el Socialista), integrado en el Grupo Mixto, avances que en ese momento de la tramitación se traducen en enmiendas o transaccionales aceptadas ${ }^{49}$.

46 Otra novedad insólita previa: el Gobierno se aseguró la aprobación apresurada del presupuesto para 2016 antes de la disolución de la X legislatura, que tuvo lugar el 27 de octubre de 2015; de forma que en la breve XI legislatura, a lo largo de toda la cual el Gobierno estaba en funciones y no podía aprobar ningún proyecto de ley (ni específicamente el proyecto de ley de PGE, de conformidad con el artículo 21.5 de la Ley 50/1997, de 27 de noviembre, del Gobierno), no fue necesario tramitar presupuesto alguno.

47 La misma situación motiva que no lleguen a presentarse en 2017 los presupuestos para el año 2018.

48 Se ha expuesto más arriba la regulación de los empates en el artículo 88 RC. En la cardíaca votación de las enmiendas de totalidad celebrada en el Pleno del Congreso el 4 de mayo de 2017, el resultado, incluido un voto telemático, es de 175 a favor y 175 en contra; se repite en segunda votación, se suspende la sesión por cinco minutos y se obtiene el mismo resultado que provoca, de conformidad con el Reglamento, que las enmiendas queden rechazadas (Diario de Sesiones n. o 49, págs. 33-34).

49 En la Comisión de Presupuestos, las votaciones del Informe de la Ponencia se ganan por 19 votos frente a 18, ver Diarios de Sesiones de Comisiones n. ${ }^{\circ} 244$ y 240, de 24 y 25 de mayo de 2017. 
Desde el comienzo del procedimiento, se multiplican las incidencias. La Mesa de la Comisión rechaza distintas solicitudes de comparecencias — primer trámite que se celebra antes de que concluya el plazo de enmiendas ${ }^{50}$ - , bien por tratarse de cargos inferiores o superiores a Secretario de Estado o Subsecretario (las preguntas que se pretendieran formular deben ser planteadas a estos cargos), o por no ser cargos públicos responsables de la gestión de los presupuestos, caso por ejemplo de los representantes de los agentes sociales, de portavoces de asociaciones de colectivos o de cargos de Ayuntamientos, que solicitaban varios grupos en número cercano a los dos centenares. Siendo el objeto de estas comparecencias que las autoridades responsables de la elaboración de los presupuestos los expliquen en las Comisiones de la Cámara, son insólitas las solicitudes de comparecientes de la sociedad civil, en elevado número por otra parte.

Las enmiendas al articulado presentadas suponen un récord absoluto, 6056 según el BOCG n. ${ }^{\circ}$ 6-7, de 11 de mayo de 2017, teniendo en cuenta que distintos grupos presentan además enmiendas o correcciones de enmiendas fuera de plazo, de las que sólo se admitirían las que fueran de subsanación de las presentadas en plazo. En definitiva, el ya apretado calendario de tramitación ha de modificarse para ampliar el plazo para emisión de informe por la ponencia del 12 al 18 de mayo ${ }^{51}$.

Previamente, la Mesa de la Comisión, con mayoría PP-Cs, había admitido a trámite las enmiendas que incorporaban una baja en la Sección 31 hasta la cuantía del crédito asignado a esta sección, entendiendo que una vez superado éste las restantes enmiendas se notificaban al Gobierno, en la medida en que suponían aumento de gasto y necesitaban su conformidad para la tramitación. Este último acuerdo, que no llegó a ejecutarse por lo que se señala a continuación, sería recurrido ante la Mesa de la Cámara por los Grupos afectados ${ }^{52}$. Entretanto, se presentaron por los distintos grupos estas enmiendas (unas 4000) como transaccionales para el debate en la Comisión, con baja en la misma Sección que el alta y la consiguiente retirada de las enmiendas iniciales ${ }^{53}$.

En realidad, lo que se produce es un cambio en la aplicación del Reglamento relajada por los usos (permitir atribuir a la Sección 31, Gastos diversos Ministerios, por encima de su cuantía presupuestada, la imperativa baja a la misma sección en la que se

50 Véase el calendario de tramitación del Proyecto de Ley de Presupuestos en BOCG Congreso, Serie A, n. ${ }^{\circ}$ 6-2.

${ }^{51} \mathrm{La}$ Ponencia aprueba la incorporación de sólo 6 enmiendas más una enmienda in voce, respecto de la cual un diputado del Grupo Socialista manifiesta su disconformidad con la inclusión en fase de ponencia. En Comisión se aprobarían 104 y en Pleno 44 transaccionales y 1 in voce.

52 Recursos desestimados por la Mesa de la Cámara, entendiendo que se habían adoptado los acuerdos de conformidad con los arts. 133 y 134 del Reglamento, y en consideración además a la autonomía de las Comisiones para la adopción de sus acuerdos.

53 Estas incidencias se denuncian por los portavoces de los grupos en cuestión de orden al inicio del debate en la Comisión de Presupuestos, véase Diario de Sesiones de Comisión n. ${ }^{\circ} 238$, de 23 de mayo de 2017 , págs. 1 y ss. 
pretende el alta ${ }^{54}$ ), que ya no es consentida por el grupo mayoritario que apoya al Gobierno, por no tener asegurado el resultado final ${ }^{55}$, cambio de prácticas provocado por la nueva composición del Congreso del que hemos mostrado varios ejemplos.

El relato de las vicisitudes en la tramitación del Proyecto de Ley de Presupuestos, sujeto a pactos coyunturales que en cualquier momento pueden deshacerse, nos lleva a formularnos una pregunta parecida a la planteada respecto de la función legislativa: ¿y si la Ley de PGE no llegara a aprobarse? ¿Es posible gobernar sin presupuestos?

Evidentemente, la solución está constitucionalmente prevista en el artículo 134.4, mediante la prórroga de los presupuestos del ejercicio anterior. Pero si el presupuesto constituye el instrumento económico de la acción política, no poder adaptarlo a los objetivos de la política interior y exterior cuya dirección atribuye al Gobierno el artículo 97 CE implica no poder desarrollar esa acción política, más allá de un mero continuismo.

Recuérdese que la aprobación de las enmiendas de totalidad al Proyecto de Ley de Presupuestos para 1996 suscitó ya un debate en este sentido, que concluyó cuando, un par de meses más tarde, el Presidente González disolvió las Cámaras y convocó elecciones ${ }^{56}$.

\section{LA FUNCIÓN DE CONTROL. LA RESPONSABILIDAD DEL GOBIERNO}

\section{Instrumentos ordinarios de control e indirizzo}

Ya hemos constatado en otro lugar ${ }^{57}$ la inadecuación de los actuales instrumentos de control a la finalidad que pretenden, esto es, verificar si la acción del Gobierno se acomoda o no al criterio del Parlamento y exigir, en caso de que el examen resulte negativo, la responsabilidad del Gobierno o imponer su cese.

Un Gobierno con el apoyo de una mayoría sólida en la Cámara no tenía por qué preocuparse de unas preguntas orales formuladas en su mayor parte por su Grupo parlamentario; de unas preguntas con respuesta escrita cuyo volumen ${ }^{58}$ ahoga su

${ }^{54}$ El art. 133.3 RC establece: «Las enmiendas al proyecto de Ley de Presupuestos Generales del Estado que supongan aumento de créditos en algún concepto únicamente podrán ser admitidas a trámite si, además de cumplir los requisitos generales, proponen una baja de igual cuantía en la misma Sección». Ello es congruente con lo dispuesto en el art. 134.1, según el cual en el debate de totalidad del proyecto quedan fijadas las cuantías globales de los estados de los Presupuestos.

55 Pueden verse en el debate en Pleno del dictamen de la Comisión las protestas de distintos portavoces, y su denuncia de que se rompe con la práctica anterior al inadmitir enmiendas por valor de 47.000 millones de euros, cuya baja se imputaba a un programa de la Sección 31 dotado con 15 millones (Diario de Sesiones n. ${ }^{\circ}$ 58, de 30 de mayo de 2017).

${ }^{56}$ Real Decreto 1/1996, de 8 de enero, de disolución del Congreso de los Diputados y del Senado y de convocatoria de elecciones.

${ }^{57}$ P. García-Escudero Márquez, «Regeneración del Parlamento, transparencia y participación ciudadana», cit., págs. 186 y ss.

58 El número de preguntas para respuesta escrita alcanzó 104.313 en la IX legislatura y «sólo» 82.289 en la X. En la XII, a 30 de junio de 2017, 14.399; a 31 de diciembre, 25.148. 
posible utilidad como instrumento de control e información; de unas interpelaciones cuyo debate modificado las ha convertido en preguntas ampliadas en un salón de sesiones casi vacío .

Sabemos que las Cámaras no se constituyen en el centro del debate político precisamente por el ejercicio de los instrumentos ordinarios de control en las sesiones semanales. Sin embargo, la nueva composición arroja algunos elementos diferenciales respecto de la anterior experiencia parlamentaria:

- las nuevas fuerzas políticas tienen gran interés en aprovechar al máximo la visibilidad que les aportan estas sesiones, para lo cual se utilizará la selección de los temas y de los ministros afectados, así como el vigor en las eventuales acusaciones

— frente a estos nuevos grupos, el Gobierno no puede utilizar la respuesta del «y tú más» en períodos anteriores (técnica del contracontrol), y tiene que acudir a ejemplos de Comunidad Autónoma o Ayuntamiento donde gobierne el grupo interpelante.

En realidad, puede decirse que las sesiones de control se componen de combates dialécticos, en los que prima el efectismo sobre el contenido de lo que se pregunta o interpela, con lo cual se pierde el sentido de accountability o rendición de cuentas de la actuación del Gobierno ante el Parlamento, de forma continuada en un régimen parlamentario, que constituye la finalidad de estos mecanismos.

Mención especial merecen las proposiciones no de ley y mociones consecuencia de interpelación. Se trata en este caso de iniciativas mediante las que se ejerce la función de indirizzo u orientación al Gobierno, pero carentes de sanción en caso de incumplimiento. Apenas si existe en el Reglamento del Senado (art. 178) la norma que establece que en los seis meses siguientes a la aprobación de una moción, el Gobierno o el órgano correspondiente deberán informar sobre el cumplimiento dado a las mismas, informe que será publicado por la Cámara. Una propuesta de reforma del Grupo Vasco pretende introducir una disposición similar en el Reglamento del Congreso, reforzada con una comparecencia ${ }^{59}$, precisamente por tener conciencia de la falta de efectividad de estos instrumentos.

59 Proposición de reforma del Reglamento del Congreso de los Diputados para el control parlamentario de acuerdos parlamentarios sin fuerza de ley (BOCG Congreso, Serie B, n. ${ }^{\circ} 80-1$, de 30 de enero de 2017), tomada en consideración el 7 de marzo: «Nuevo Título XII, Del control sobre las Proposiciones no de Ley, Mociones y demás resoluciones aprobadas por la Cámara tanto en Pleno como en Comisión. Nuevo artículo 203 bis. 1. Durante el primer mes hábil de cada período de sesiones el Gobierno remitirá a la Cámara un informe detallado relativo a la situación y grado de cumplimiento de cada una de las proposiciones no de ley, mociones y resoluciones aprobadas tanto en Pleno como en Comisiones en el período de sesiones anterior, así como las pendientes de cumplimiento de periodos anteriores. 2. En la quincena posterior a la entrada en el Registro de la Cámara del Informe comparecerá en la Comisión de Reglamento un representante del Ejecutivo para explicar el citado informe y responder a los requerimientos de los Grupos Parlamentarios». 
A pesar de ello, por el hecho de implicar una votación de la Cámara, se han convertido en el medio preferido por la oposición para hacer visible la nueva composición, de ahí que hayan aumentado de forma exponencial las proposiciones no de ley presentadas y aprobadas, sobre todo en comisión: si en el total de la X legislatura se aprobaron en las distintas comisiones un total de 639 proposiciones no de ley, sólo en los dos primeros periodos de sesiones de la XII legislatura se supera el $80 \%$ de esta cifra, con 515; transcurrido el tercer período, ya son más del 100\%, 734 a 31 de diciembre de 2017, de 2.746 presentadas. Serán en muchos casos expresión de medidas que no llegarán a ejecutarse, pero se utilizan como altavoz político distintas formaciones.

\section{Las comisiones de investigación}

Las comisiones de investigación constituyen un medio extraordinario de control, aunque no son definidas como tales por la Constitución, que únicamente establece que versarán sobre cualquier asunto de interés público. Sus facultades exorbitantes (obligación de comparecer a su requerimiento bajo sanción penal) las distinguen claramente de las comisiones especiales de estudio, de manera que su objeto suele recaer sobre escándalos políticos o graves catástrofes.

¿Qué novedades nos aporta la nueva composición del Congreso respecto de la práctica anterior?

En primer lugar, dado que el Grupo que apoya al Gobierno no cuenta con mayoría estable en la Cámara, será mucho más fácil la creación de comisiones de investigación que a lo largo de estos cuarenta años, o dicho de otra manera, podrán crearse contra la voluntad del Gobierno ${ }^{60}$. La llave para esta creación la tiene el principal partido de la oposición, el Grupo Socialista.

Como consecuencia de la mayoría adversa, en el primer periodo de sesiones de 2017 se crean tres comisiones de investigación ${ }^{61}$, cuyo funcionamiento llega a coincidir en el tiempo, algo insólito en términos cuantitativos ${ }^{62}$. Además, estas comisio-

${ }^{60}$ También en el número elevado (28) de comisiones de investigación constituidas desde 2015 en las Asambleas autonómicas se pone de manifiesto su composición fragmentada.

61 Citadas en nota 18. Además de la ya citada Comisión permanente no legislativa de calidad democrática, la lucha contra la corrupción y reformas institucionales y legales, en cuyo seno funciona la Subcomisión citada en nota 37.

${ }^{62}$ Hay que remontarse a la V legislatura, en un período políticamente complicado, para la creación de tres comisiones de investigación (sobre fondos asignados a la Dirección de la Guardia Civil, sobre la situación del patrimonio de D. Mariano Rubio y sobre el proceso de privatización de la empresa pública Intelhorce). Antes hubo tres también en la II, sobre Rumasa, catástrofes aéreas en Barajas y financiación de partidos políticos. Se crearon dos en la VI, IV y I legislaturas, y 1 en las legislaturas VIII, VII y III. Las últimas Comisiones de investigación en el Congreso fueron en la VIII legislatura, sobre el 11 de marzo de 2004, y en la VII, sobre Gescartera. En el Senado, se constituyeron tres en la I, 6 en la II, 2 en la III y la IV, siendo la última la abortada en la V legislatura sobre la creación y actuación de los GAL. La única Comisión Mixta de Investigación constituida, sobre el síndrome tóxico, se crea en la II legislatura. En total, 14 en cada Cámara en 11 legislaturas y 1 mixta Congreso-Senado. 
nes pretenden controlar al Gobierno o a su partido principalmente por hechos anteriores al mandato actual, lo que plantea algunas dudas de coherencia con la finalidad del instituto: así, las actuaciones del Ministerio del Interior en otras legislaturas y bajo otros responsables, o también la financiación del Partido Popular, cuyo ámbito temporal sería tema controvertido desde el comienzo de los trabajos y llevado por el Grupo Popular ante la Mesa como cuestión previa ${ }^{63}$. Incluso el objeto de la investigación puede alcanzar a la actividad de Gobiernos anteriores de distinto signo, como en el caso de la crisis financiera,

Habría que reflexionar sobre si las comisiones de investigación tienen por único objeto dilucidar responsabilidades políticas (claramente diferenciadas de las penales por la Constitución) o pueden realizar otro tipo de investigaciones (sobre cualquier asunto de interés público, art. $76 \mathrm{CE}$ ), y si tiene sentido exigir esa responsabilidad respecto de períodos anteriores. Está claro que en cualquier caso ése es el modelo que predomina en estos momentos.

Tampoco funcionan con la misma claridad que en otros tiempos las relaciones con la Administración de Justicia. Es sabido que la Constitución admite la coexistencia de ambas investigaciones, la parlamentaria y la judicial. Pero, por primera vez, por distintas circunstancias (a las que no es ajena la judicialización de la política), la primera no va por delante de la segunda, y en consecuencia nos encontramos con diferentes supuestos inéditos: investigación sobre hechos en los que ha recaído un sobreseimiento o archivo de las actuaciones; solicitud de citación de personas que se encuentran en prisión preventiva o libertad condicional (esto ya había ocurrido); petición de documentación que consta en autos judiciales en asuntos sub iudice.

También constituye una novedad que el Consejo General del Poder Judicial invoque el artículo 399 de la Ley 6/1985, del Poder Judicial ${ }^{64}$, en relación con la comparecencia, ante una Comisión de investigación, de un juez por motivos ajenos a su función jurisdiccional (cargos públicos ejercidos), comparecencia a la que está obligado por el artículo 76 de la Constitución y la Ley Orgánica 5/1984, de 24 de mayo.

Una característica del periodo examinado es que funcionan simultáneamente comisiones de investigación en el Congreso y en Cámaras autonómicas sobre temas conexos, lo que lleva también a multiplicar las peticiones de documentación a éstas, que a veces se adelantan en su actividad.

Un dato más revelador de la nueva situación política es que, constituida una comisión contra su voluntad en el Congreso, el Grupo Popular, con mayoría absoluta en el Senado, contraataca con la creación en esta Cámara de otra, en la que la

63 La Mesa rechazaría la solicitud, merced al voto de Cs, sobre la base de que el acuerdo del Pleno de creación de la comisión no establecía limitación (véase El País y El Mundo, 13 de junio de 2017).

${ }^{64}$ Art. 399 LOPJ. 1. Las autoridades civiles y militares se abstendrán de intimar a los Jueces y Magistrados y de citarlos para que comparezcan a su presencia. / /Cuando una Autoridad civil o militar precise de datos o declaraciones que pueda facilitar un Juez o Magistrado, y que no se refieran a su cargo o función, se solicitarán por escrito o se recibirán en el despacho oficial de aquél, previo aviso. 
investigación de la financiación del Partido Popular se extiende en general a todos los partidos políticos ${ }^{65}$.

\section{La reprobación de ministros y otras autoridades}

Como es sabido, la reprobación de los ministros no está prevista en la Constitución, conforme a la cual la responsabilidad solidaria del Gobierno (art. 108) sólo puede exigirse a través de la moción de censura constructiva regulada en el artículo $113^{66}$. En caso de aprobarse la moción, al igual que si se deniega una cuestión de confianza, «el Gobierno presentará su dimisión al Rey», según dispone el artículo $114^{67}$.

Sin embargo, a partir de la II legislatura, comienzan a admitirse a trámite iniciativas (principalmente proposiciones no de ley o mociones) que incluyen en su texto la reprobación de algún Ministro. La primera reprobación aprobada sería en el Senado el 18 de diciembre de 2007, de la Ministra de Fomento Magdalena Alvarez.

La XII legislatura inaugura la reprobación de ministros en el Congreso. Más aún, el 18 de octubre de 2016, la Comisión de Interior aprueba una proposición no de ley del Grupo Mixto para reprobar al Ministro del Interior en funciones e instar su cese de inmediato «por sus acciones y actitudes antidemocráticas y faltas de ética política, en contra de quienes piensan diferente del Ministro» ${ }^{68}$. Cuando se publica la aprobación, el reprobado ya no era ministro en funciones, sino ex ministro ${ }^{69}$.

Ya en el segundo período de sesiones, el 16 de mayo de 2017 el Pleno del Congreso aprueba una moción consecuencia de interpelación del Grupo Socialista, en la que se acuerda la reprobación del Ministro de Justicia ${ }^{70}$. Se reprueba igualmente

${ }^{65}$ Comisión de Investigación sobre la financiación de los partidos políticos y el estudio de las medidas que permitan avanzar en el compromiso de transparencia adoptado y que, a su vez, impidan supuestos de financiación ilegal en el futuro. Creada por el Pleno el 5 de abril de 2017 y constituida el 6 de junio de 2017 (una vez que la del Congreso echó a andar), no participaron en sus trabajos los grupos de la oposición.

${ }^{66}$ Art. 113.1. El Congreso de los Diputados puede exigir la responsabilidad política del Gobierno mediante la adopción por mayoría absoluta de la moción de censura.

${ }^{67}$ A favor de la introducción en el Reglamento del Congreso de un procedimiento de exigencia de responsabilidad política de los miembros del Gobierno, A. Torres del Moral, «Responsabilidad política de los Ministros», El Mundo, 1 de junio de 2017. Entiende que para imponer el cese en caso de que se apruebe una reprobación no es necesaria una reforma constitucional, lo cual es discutible.

${ }^{68}$ BOCG Congreso, Serie D n. ${ }^{\circ} 46$, de 8 de noviembre de 2016, pág. 17.

69 Los nuevos miembros del Gobierno fueron nombrados por Real Decreto 417/2016, de 3 de noviembre.

70 «Por su responsabilidad directa en estos nombramientos [en el Ministerio Fiscal], por su injerencia en estas causas judiciales y por unas actuaciones que menoscaban la confianza de los ciudadanos en el Ministerio Fiscal y dificultan el trabajo de los miembros de esta institución que luchan cada día contra la corrupción». 
la actuación del Fiscal General del Estado (se insta al Gobierno a proceder a su cese por incumplimiento grave y reiterado de sus funciones), y del Fiscal Jefe de la Fiscalía Especial contra la Corrupción y la Criminalidad Organizada, instando al Gobierno a su remoción de acuerdo con lo dispuesto en el Estatuto Orgánico del Ministerio Fiscal $^{71}$.

Más adelante, se aprueba la reprobación del Secretario de Estado de Seguridad (20 de junio) y posteriormente (29 de junio) la del Ministro Montoro, tras la sentencia del Tribunal Constitucional sobre la amnistía fiscal aprobada por Decreto-ley ${ }^{72}$.

Quizá la novedad con respecto a la época constitucional anterior no sea que se apruebe por primera vez en el Congreso de los Diputados una reprobación a un ministro, sino que la mayoría de oposición ha comprendido que puede utilizar estas iniciativas como un mecanismo más de control, cuasiordinario, del que se sabe carece de consecuencias jurídicas (su aprobación no implica el cese del ministro), pero que puede ser explotado desde un punto de vista político, de cara a la opinión pública. El incremento de las aprobadas puede llevar a la trivialización de la reprobación como instrumento de control.

También debe destacarse que la reprobación se extienda desde los miembros del Gobierno a autoridades inferiores y a cargos nombrados por él, en estos casos distinguiendo que lo que se reprueba es la actividad. Más aún, que el reprobado sea el Fiscal General del Estado o un Fiscal Especial, cargos nombrados por el Gobierno, pero de los que se propugna la independencia. No olvidemos que la Constitución regula el Ministerio Fiscal en el Título VI, como órgano auxiliar del Poder Judicial.

\section{La moción de censura testimonial que se gana en la calle}

No son muchos los casos de utilización de la moción de censura en el periodo de vigencia de nuestra Constitución hasta la XII legislatura. Sólo dos, en distintas circunstancias y con distintos resultados, no en cuanto al éxito de la moción, pues en ambos casos fue rechazada, sino en cuanto al rédito político sacado de la misma.

Son sabidos los requisitos reforzados establecidos por el artículo 113 de la Constitución para preservar la estabilidad gubernamental, como es propio de un régimen parlamentario racionalizado: presentación por una décima parte de los miembros de la Cámara, inclusión de un candidato alternativo, mayoría absoluta para su aprobación, período de enfriamiento de cinco días desde la presentación hasta la votación, prohibición en caso de rechazo de que sus signatarios presenten otra durante el mismo período de sesiones.

${ }^{71}$ BOCG Congreso, Serie D n. ${ }^{\circ}$ 159, de 24 de mayo de 2017, pág. 24.

72 STC 73/2017, de 8 de junio. 
Las mociones hasta ahora presentadas tenían como objetivo reforzar al líder de la oposición, lo que se considera consiguió Felipe González en 1980, pero no Antonio Hernández Mancha en $1987^{73}$.

Treinta años después, en el breve periodo que examinamos de la XII legislatura, la moción presentada por 37 diputados del GP UP-EC-EM presenta una motivación más compleja. Aunque las consideraciones que le sirven de exposición de motivos van obviamente dirigidas contra el Gobierno y el Partido Popular, su calendario se plantea más bien en relación con el principal grupo de la oposición y las circunstancias internas del Partido Socialista Obrero Español, pues, aunque anunciada con anterioridad, se presenta el 19 de mayo de 2017, inmediatamente antes de la celebración de elecciones primarias en el seno de dicho partido, lo que podía dificultar la presentación de una moción alternativa en el plazo de dos días previsto por el artículo 113.3 de la Constitución.

Aunque la diferencia fundamental en este caso reside en que la oposición hipotéticamente sí podría obtener mayoría absoluta holgada para aprobarla, por primera vez tiene carácter decisivo el carácter constructivo de la moción, pues difícilmente grupos que se disputan el mismo espacio electoral apoyarán al candidato del otro, ni siquiera negociado. Se trata entonces de adelantarse en la presentación a otras mociones posibles y a la vez obligar a los distintos grupos, pero fundamentalmente al Socialista, a posicionarse en una votación dirigida contra el Presidente del Gobierno ${ }^{74}$. Nótese que por primera vez no es el primer grupo de la oposición el que presenta la moción, obviamente porque hasta ahora ningún otro Grupo contaba con los 35 diputados necesarios.

La moción de censura presentada es calificada por el Grupo solicitante de mediática $^{75}$, con el objetivo de rentabilizar el malestar social, y se pretende reforzar la iniciativa con apoyos extraparlamentarios, para lo que se convoca una movilización ciudadana en la Puerta del Sol a los dos días de su presentación, al objeto de mantener la centralidad de la agenda política.

${ }^{73}$ La visión de A. Hernández Mancha, en «El dedo de Fraga y la moción de censura», $A B C, 17$ de junio de 2017.

${ }^{74}$ De hecho, un supuesto argumentario interno de Podemos sobre la moción de censura, reproducido en $A B C$ el 4 de junio de 2017, afirma que se aspira a que «la moción deje de verse en clave de espectáculo, sino en clave de relaciones posibles entre Podemos y PSOE». «Es muy importante insistir en que la moción de censura no es sólo un mecanismo «constructivo», es también un mecanismo parlamentario que permite llevar la visibilización de una oposición y una alternativa de país al debate en la cámara», como se hizo en mociones anteriores y «que votar en contra de la moción es votar a favor del Gobierno (de la indignidad)».

75 El editorial del diario El Mundo de 9 de junio de 2017, titulado «La moción de censura como espectáculo», referida a la debatida la víspera en la Asamblea de Madrid, afima que ésta «inaugura las mociones de censura concebidas como espectáculo y como un modo legítimo y democrático de intentar un cambio de Gobierno que pasa por dificultades», en la que se deja «bien claro hacia quién se dirigía la moción». En palabras de Pablo Iglesias antes de iniciarse el debate, «queremos ver si el PSOE está enfrente del PP». 
El tiempo transcurrido desde la anterior se pone de manifiesto en la propia afirmación de que la moción de censura se gana en la calle, pues las otras podían tener también un objetivo mediático y de visibilización, pero parlamentaria. Y la lucha no era contra los partidos de la oposición, sino contra el Gobierno.

\section{LA FUNCIÓN DE NOMBRAMIENTO}

La función de integración de otros órganos que la Constitución y distintas leyes atribuyen a las Cámaras se ve profundamente afectada por la nueva composición del Congreso de los Diputados.

Cierto es que los Grupos Popular y Socialista suman 218 miembros, superando los 210 que representan los tres quintos exigidos por la Constitución para el nombramiento de miembros de órganos constitucionales (Tribunal Constitucional, Consejo General del Poder Judicial) y de relevancia constitucional (Tribunal de Cuentas, Defensor del Pueblo).

Es cierto también que, en el sistema de cuotas vigente durante el bipartidismo ${ }^{76}$, en ocasiones se cedía la propuesta de algún miembro a un tercer grupo, sobre todo en períodos sin mayoría absoluta. Pero creemos que en la nueva época no sería defendible ante la opinión pública un acuerdo de reparto que dejara fuera al tercer Grupo por número de miembros o incluso al cuarto. La composición plural de la Cámara debería hallar reflejo en otros órganos, y queda abierto cómo se producirá ese reflejo en la práctica.

Se comprueba, pues, que aun con un bipartidismo sustituido por un cuatripartidismo, las dos mayores formaciones políticas podrían seguir alcanzando las mayorías constitucionalmente requeridas como garantía de consenso, que han derivado hacia otros derroteros. No confiamos no obstante en que la nueva composición conduzca hacia el nombramiento de personas independientes que susciten amplio asentimiento, sino a que la propuesta partidista sea más plural.

La primera elección por el Pleno debiera producirse como consecuencia de la aprobación de la Ley 5/2017, por la que se modifica la Ley 17/2006, de 5 de junio, de la radio y la televisión de titularidad estatal, para recuperar la independencia de la Corporación RTVE y el pluralismo en la elección parlamentaria de sus órganos, a que nos hemos referido supra en el apartado III.2.b). En este caso, la elección de seis miembros del Consejo de Administración de la Corporación RTVE requiere dos tercios de los miembros del Congreso (mayoría absoluta en segunda vuelta, pasados quince días, previa propuesta de al menos la mitad de los grupos parlamentarios), cifra que alcanzarían, si se pusieran de acuerdo conjuntamente, los Grupos Popular, Socialista y Cs o UP, pero también aquí cabe pensar en un reparto más plural que

${ }^{76}$ Me he ocupado de esta cuestión en P. García-Escudero Márquez, «La problemática de la integración de órganos por el Parlamento», Asamblea, n. ${ }^{\circ} 27,2012$, págs. 11-23. 
alcance al menos a los cuatro grupos; la alternativa a estas posibilidades es, una vez más, el bloqueo institucional.

\section{LA FUNCION INTERNACIONAL}

\section{Autorización de convenios internacionales}

En una materia tan rutinaria y pacífica como hasta ahora era la tramitación de convenios internacionales, enmarcada en el artículo 94.1 de la Constitución y partiendo de que la dirección de la política internacional corresponde al Gobierno, también se han producido novedades en el corto período de la XII legislatura que examinamos.

Cabe citar al respecto la confusa tramitación del Convenio europeo sobre protección de animales de compañía, hecho en Estrasburgo el 13 de noviembre de 1987, así como Reserva y Declaración que España desea formular. Como puede verse por el título de la iniciativa, la solicitud de autorización se remite por el Gobierno al Congreso acompañada de una reserva sobre corte de la cola de razas cazadoras, y de una declaración de reserva de derechos en relación con Gibraltar ${ }^{77}$.

La Ponencia por mayoría acepta la supresión de la reserva, propuesta por UP-EC$\mathrm{EM}^{78}$, es decir, se derrota la posición del Gobierno. El dictamen de la Comisión de Asuntos Exteriores vuelve a incluir la reserva con un texto transaccional $^{79}$, que es suprimido de nuevo por el Pleno del Congreso ${ }^{80}$. La reserva reaparece en el dictamen de la Comisión del Senado ${ }^{81}$, Cámara en la que el GPP cuenta con mayoría absoluta, y es suprimida otra vez por el Pleno ${ }^{82}$, de forma que la autorización coincide con la concedida por el Congreso y no es necesario constituir Comisión Mixta de conciliación al amparo del artículo 74.2 de la Constitución.

Este ejemplo de vaivén, absolutamente inusual y que provoca cierta perplejidad, más allá de las motivaciones políticas que pudieran originar cada cambio de criterio, pone de manifiesto las vicisitudes que puede atravesar cada iniciativa propuesta por el Gobierno hasta llegar a su aprobación, incluso en una materia tan poco controver-

77 BOCG Cortes Generales n. ${ }^{\circ}$ A-17, de 16 de diciembre de 2016.

78 BOCG Congreso n. ${ }^{\circ}$ C-6-2, de 14 de marzo de 2017.

79 BOCG Congreso n. ${ }^{\circ}$ C-6-4, de 15 de marzo de 2017.

80 BOCG Congreso n. ${ }^{\circ}$ C-6-5, de 29 de marzo de 2017. En el debate interviene por UP-EC-EM el portavoz Pablo Iglesias (que no había tomado la palabra en el punto inmediatamente anterior en el orden del día, convalidación del Real Decreto-Ley 4/2017, sobre estiba, al que nos hemos referido supra porque el Pleno rechazó la convalidación) para oponerse al corte de la cola de los perros. Ello muestra la relevancia que cada Grupo otorga a los distintos temas en función de sus propios criterios (véase Diario de Sesiones Pleno Congreso n. ${ }^{\circ}$ 39, de 16 de marzo de 2017).

81 BOCG Senado n. ${ }^{\circ} 91 \_818$, de 10 de mayo de 2017.

82 BOCG. Senado Núm. 94_850, de 16 de mayo de 2017. 
tida — salvo excepciones con algún componente ideológico- como la autorización de convenios internacionales.

Vicisitudes aportadas como botón de muestra, por augurar una legislatura compleja para un Gobierno en minoría.

\section{Política de la Unión Europea}

También en relación con la ratificación de un convenio internacional, pero éste derivado de nuestra pertenencia a la Unión Europea, se plantean cuestiones de procedimiento que anuncian una legislatura complicada. Se trata del Acuerdo Económico y Comercial Global entre Canadá, por una parte, y la Unión Europea y sus Estados miembros, por otra, hecho en Bruselas el 30 de octubre de 2016, conocido como CETA por sus siglas en inglés.

A este acuerdo — bien es verdad que no exento de polémica en otros países-, que podía considerarse incluido en las relaciones internacionales sobre las que hasta ahora existía una política de Estado generalmente compartida, se presenta una enmienda a la totalidad por el Grupo UP-EC-EM, que propone la denegación de la autorización, esto es, la propuesta de no ratificación del Acuerdo, por entender «que los capítulos 8 y 26 del Acuerdo violan en grado sumo preceptos fundamentales del orden constitucional establecido, además de suponer cesiones notables en materia de soberanía popular, que sólo merecen el rechazo por parte de esta Cámara» ${ }^{83}$.

Junto a esta enmienda, el citado Grupo solicita el control previo de la constitucionalidad del acuerdo previsto en el artículo 95.2 CE. Tras varias peticiones de reconsideración de acuerdos de la Mesa, la propuesta de requerimiento al Tribunal Constitucional es incluida en el orden del día del Pleno y debatida conjuntamente con la enmienda de totalidad ${ }^{84}$.

Finalmente, la enmienda a la totalidad es rechazada por 84 votos a favor, 262 en contra y una abstención, y la propuesta de requerimiento de inconstitucionalidad por 86 votos a favor y 258 en contra, es decir, algo más de veinte votos se suman a los del Grupo proponente.

¿Qué revela de novedoso este ejemplo? Falta de consenso por parte de un grupo parlamentario respecto de políticas acordadas en el seno de la Unión Europea; disenso en política internacional que, como se ha dicho, suele considerarse política de Estado en la que los dos grandes grupos — con alguna excepción- marchaban de

83 BOCG Congreso, Serie C n. ${ }^{\circ}$ 36-2, de 9 de mayo de 2017.

${ }^{84}$ Diario de Sesiones Pleno n. ${ }^{\circ} 55$, de 18 de mayo de 2017. En este Diario pueden verse las protestas del portavoz de UP-EC-EM, Sr. Bustinduy, por las circunstancias de la tramitación de su iniciativa. La propuesta de requerimiento se fundamenta en la creación por el Acuerdo de tribunales de inversiones (ICJ), por entender que se trata de una justicia paralela que vulnera el principio de unidad jurisdiccional, y de comités mixtos de regulación con potestad normativa y vinculante. La posición contraria, que comparto, se funda en que el Acuerdo se autoriza en el marco de la cesión de competencias constitucionales ya otorgadas en favor de la Unión Europea. 
acuerdo; utilización de mecanismos oxidados como la enmienda a la totalidad respecto de convenios internacionales (sólo se han presentado 26 en todas las legislaturas anteriores) o hasta ahora excepcionales: el recurso al artículo 95.2 CE sólo ha dado lugar a dos declaraciones del Tribunal Constitucional en casi cuarenta años, en 1992 y 2004, en ambos casos a requerimiento del Gobierno y respecto de tratados que suponen o pretendían suponer un paso adelante en la integración europea, el Tratado de Maastricht y el Tratado por el que se establece una Constitución para Europa, respectivamente.

En la tramitación se manifiestan virajes en la postura del Grupo Socialista, que entretanto ha celebrado su Congreso Federal y elegido nuevo Secretario General. En el dictamen de la Comisión, el GS vota a favor, para anunciar a continuación los medios de comunicación que en el Pleno lo hará en contra, voto que se transforma en abstención tras una entrevista en Madrid del Secretario General del Partido Socialista, Pedro Sánchez, con el comisario europeo Moscovici. La abstención, acordada por la Comisión Ejecutiva Federal el 26 de junio, se materializa en la votación plenaria del día 29.

Nuevas perspectivas de mayor protagonismo parlamentario y de utilización política de las decisiones europeas se abren, pues, en un Parlamento fragmentado, incluso - como decíamos al principio de este epígrafe - en una función tan rutinaria y de consenso como hasta ahora ha sido la internacional de las Cortes Generales.

\section{CONCLUSIÓN: ¿SE PUEDE GOBERNAR CON UN PARLAMENTO FRAGMENTADO?}

Los acontecimientos recogidos en las páginas anteriores no pretenden conformar una crónica. Se presentan como ejemplos que muestran hasta qué punto el Parlamento actual presenta fuertes diferencias con el que hemos conocido durante cerca de cuarenta años. Se plantean incidencias inéditas que reclaman muchas veces nuevas soluciones, no contenidas en la Constitución ni en los Reglamentos de las Cámaras.

En el período de Gobierno en funciones, se han constatado las supuestas lagunas del artículo $99 \mathrm{CE}$, que había funcionado sin problemas en los decenios anteriores, cuando los resultados electorales permitían investir un Presidente del Gobierno con relativa facilidad; sin perjuicio de que, en mi opinión, las carencias observadas no precisan echar abajo el texto constitucional: en el artículo que nos ocupa bastaría con sustituir el dies a quo y el plazo que conducen a la disolución automática.

En el desarrollo posterior de la XII legislatura, además de nuevas interpretaciones de los preceptos constitucionales que podrían requerir alguna aclaración en caso de reforma (objeto de las comisiones de investigación, exigibilidad de responsabilidad sobre periodos anteriores de gobierno), podemos apreciar: 
— cierta colisión o conflicto entre la forma tradicional de aplicación de la normativa constitucional y reglamentaria, diseñada para la protección de las minorías frente a un Ejecutivo y un grupo mayoritario fuertes: la minoría que reclama la protección de sus derechos es ahora la que apoya al Gobierno, y

- una puesta en uso de mecanismos infrautilizados, previstos para mantener la estabilidad del Gobierno (el art. 134.6 CE, que le otorga la facultad de impedir la tramitación de iniciativas presupuestarias) o para defender sus competencias que considera invadidas (el conflicto entre órganos constitucionales ante el Tribunal Constitucional),

- a la vez que se potencian los mecanismos de control y responsabilidad aunque sea de forma testimonial (reprobación de ministros y otros cargos, moción de censura sin posibilidad de éxito).

Por el buen funcionamiento del sistema, habrá que intentar llegar a un equilibrio entre un Gobierno que se deje controlar y una Cámara que le permita gobernar. Un primer paso en esta dirección representó la aprobación de la Ley de Presupuestos Generales del Estado para 2017 ${ }^{85}$. Lo contrario llevará a una paralización (legislativa, pero no sólo) de la que se han dado ejemplos en Parlamentos autonómicos con Gobierno en minoría, que en suma, tras el paso dificultoso del tiempo, no conduce sino a la disolución anticipada.

Title:

A new fragmented Parliament for the 40th anniversary of the Constitution

Summary:

I. Introduction. II. The end of the two-party system does not only affect the composition of the plenary and commissions. III. Legislative function: can a Government rule without law-making? IV. Budgetary function: difficulties to approve the budget. V. Supervisory power. Government accountability. VI. Nomination power. VII. Foreign policy. VIII. Conclusion: can a Government rule with a fragmented parliament?

${ }^{85}$ No han seguido el mismo camino, o por lo menos lo harán con retraso, los presupuestos de 2018, no presentados ni aprobados en plazo; bien es verdad que el período para su tramitación y aprobación ha coincidido con fechas ocupadas en otras vicisitudes políticas. 


\title{
Resumen:
}

Próxima la celebración de los cuarenta años de la aprobación de la Constitución, el fin del cuasibipartidismo ha generado un Congreso de los Diputados de composición fragmentada, en la que el Gobierno no cuenta con una mayoría suficiente para gobernar, lo que se refleja no sólo en el funcionamiento, sino también en el desempeño de las funciones constitucionales de las Cortes Generales. Este artículo estudia algunas cuestiones suscitadas en los primeros períodos de la XII legislatura iniciada a fines de 2016, como ejemplos que muestran las fuertes diferencias con el Parlamento conocido hasta ahora, pues se plantean cuestiones inéditas que reclaman a veces nuevas soluciones, no contenidas en la Constitución ni en los Reglamentos de las Cámaras. Si no se logra un equilibrio entre un Gobierno que se deje controlar y un Parlamento que permita gobernar, se produce la paralización política propia de un Gobierno en minoría, que no conduce sino a una disolución anticipada.

\begin{abstract}
:
Approaching forty years of the Spanish Constitution, the two-party system has been replaced in the Congress of Deputies by a fragmented composition so that the Government does not possess a sufficient majority, which upsets not only the modus operandi, but even the performance of the constitutional functions of the Spanish Parliament. This essay analyses some issues that have arisen in the current term since the last elections, as examples that show the strong differences with the Parliament known till now. Unprecedented questions require sometimes solutions not foreseen in the Constitution or the Rules of Procedure. If a balance is not achieved between a Government that allows to be controlled and a Parliament that allows to rule, comes the standstill of a minority Government, which will probably lead to an early dissolution.

\section{Palabras clave:}

parlamento fragmentado, Gobierno en minoría, funciones de las Cámaras, Congreso de los Diputados
\end{abstract}

\section{Key words:}

fragmented Parliament, minority Government, Parliament's functions, Spanish Parliament, Congress of Deputies. 